\title{
Strategies on Teaching Reformation for Mechanical Manufacturing Technology
}

\author{
Guohua Qin ${ }^{\mathrm{a},{ }^{* 1}}$, Shiping Sun ${ }^{\mathrm{a},{ }^{* 2}}$, Haichao Ye ${ }^{\mathrm{a},{ }^{* 3}}$, Dong $\mathrm{Lu}^{\mathrm{a},{ }^{* 4}}$ \\ ${ }^{a}$ School of Aeronautical Manufacturing Engineering, Nanchang Hangkong University, Nanchang, China
}

\begin{abstract}
Mechanical manufacturing technology is a compulsory subject of mechanical engineering specialty and one of important processional fundamental course. Therefore, the course reformation is significant in the entire higher education reformation process so that new training plan can successfully carried out to train high quality talent. A novel course construction and content are proposed from the easy to the difficult. On the other hand, the analogy teaching method as well as the guide teaching method is created to attract students' attention to mechanical manufacturing technology. The proposed reformation strategies for mechanical manufacturing technology can help student to improve basic abilities of analyzing and solving problem.
\end{abstract}

Index Terms: Mechanical Manufacturing Technology; Teaching Reformation; Teaching Time; Course Content; Teaching Method

(C) 2011 Published by MECS Publisher. Selection and/or peer review under responsibility of the International Conference on E-Business System and Education Technology

\section{Introduction}

The course construction of fundamentals of mechanical manufacturing technology is not only an important component of "study and practice of talent training plan and teaching reformation for mechanical specialty" of "twenty-one century oriented research plan of teaching reformation" of the ministry of education of the people's republic of china, but also a new professional fundamental course required for training modern senior mechanical manufacturing professions and management talents since china higher education specialty catalogue has been modified to satisfy the social development requirement.

In 1998, the ministry of education enacted the new specialty catalogue of higher educational school. The catalogue incorporated mechanical manufacturing technology and equipment, mechanical design and manufacturing, mechanical and electronic engineering into a new wide caliber specialty which is called as mechanical design manufacturing and automation [1]. The wide caliber specialty required a batch of new courses to consist with itself. The successful realization of talent training can rely on the reasonable course system. Therefore, the course reformation is important in the entire process of higher education reformation.

The course of fundamentals of mechanical manufacturing technology is established to accord with the higher education specialty catalogue. It was reformed from old four courses in mechanical manufacturing Corresponding author:

| E-mail address: ${ }^{* 1}$ qghwzx @ 126.com; ${ }^{* 2}$ sunsping@126.com; ${ }^{* 3}$ xxjy2000@ 163.com; ${ }^{* 4}$ ludong80@ gmail.com 
technology course system, i.e., mechanical manufacturing engineering, jig and fixture design, metal cutting principle and cutting tool, and metal cutting machine tools.

The course reformation went though two stages. The original consideration of the first reformation stage is to shorten teaching times [2]. Therefore, many uniform contents can be directly cancelled from old four courses. The reformation virtually belongs to the mechanical mixture. Many higher schools carried out this mechanical mix teaching reformation to combine metal cutting machine tools, mechanical manufacturing engineering with metal cutting principle and cutting tool [3,4]. Some higher schools mixed metal cutting principle and cutting tool, mechanical manufacturing engineering, metal cutting machine tools with jig and fixture design [5,6].

The mechanical mix reformation can to a certain extent decrease teaching times. However, some independent contents can again occur in many multi-discipline courses of manufacturing fields. Thus, the second reformation was naturally the organic integration stage. Under the guidance of the important idea of taking the road of combining leaning with research and production, many higher schools integrated old four courses into one course of fundamentals of mechanical manufacturing technology [7-9].

However, too much knowledge points can still be distributed in the teaching contents of the reformed course(s). The limit teaching times cause students not to master basic theories and technologies of mechanical manufacturing. Under the support of the teaching transformation research project of Jiangxi province, a different course modification scheme is further proposed to create old four courses into mechanical manufacturing technology and mechanical manufacturing equipment, respectively. Here, the authors will emphasize the teaching reformation on mechanical manufacturing technology.

\section{Construction of Teaching Contents}

In order to meet the training requirement of higher education, the valid course reformation is good for the improvement of teaching quality. However, the course can take teaching contents as a core. Consequently, a novel course system is established for mechanical manufacturing technology, as shown in Table 1.

Whether traditional machining methodology or modern manufacturing system, only can it use machining process to link machine tool, jig and fixture, cutting tool with measuring tool. Mechanical manufacturing must take process planning as the foundation. This is an important rule from many years of practical experience. Therefore, mechanical manufacturing technology should focus on mechanical manufacturing principles and methods.

In the process of constructing new course system, we pay attention to the choiceness and reformation of teaching contents such that we discard the mathematical deduction of the sophisticated theories. Our purpose of course reformation is to strengthen the engineering theory, widen the range of knowledge, reflect the development of new technologies, and enhance the syntheses of teaching contents. The contents are set from the easy to the difficult so that students can completely understand the entire process of mechanical manufacturing. Based on this reformation strategy, we wrote a textbook of mechanical manufacturing technology. It is first time published four thousand volumes by the national defense industry press in August 2009 [10]. For combination of theory with practice and practicability of talent training, the textbook was second time republished two thousand volumes by the same press in August 2010 [11]. 
Table 1 . The course system

\begin{tabular}{|c|c|c|}
\hline $\begin{array}{l}\text { Sequence } \\
\text { Number }\end{array}$ & $\begin{array}{c}\text { Course } \\
\text { Construction }\end{array}$ & Teaching Contents \\
\hline 1 & Basic concepts & $\begin{array}{l}\text { - Cutting motion } \\
\text { - Cutting variables } \\
\text { - Geometric parameters of cutting layer } \\
\text { - References } \\
\text { - Metal cutting tool and reference system for static angles of cutting tool } \\
\ldots . .\end{array}$ \\
\hline 2 & $\begin{array}{l}\text { Metal cutting } \\
\text { principle }\end{array}$ & $\begin{array}{l}\text { - Metal cutting process } \\
\text { - Cutting force } \\
\text { Cutting heat and cutting temperature } \\
\text { - Cutting tool wear and tool life } \\
\text { - Selection of metal cutting conditions } \\
\ldots .\end{array}$ \\
\hline 3 & $\begin{array}{l}\text { Machining } \\
\text { accuracy }\end{array}$ & $\begin{array}{l}\text { - Conception of machining accuracy } \\
\text { - Influence of geometric error of machining complex on machining accuracy } \\
\text { - Influence of physical factors of machining complex on machining accuracy } \\
\text { - Statistical analysis of machining error } \\
\text { - Methods for machining accuracy improvement } \\
\ldots . . .\end{array}$ \\
\hline 4 & Surface quality & $\begin{array}{l}\text { - Conception of surface quality } \\
\text { - Factors affecting surface roughness and its improvement methods } \\
\text { - Factors affecting physico-mechanical state of surface layer and its improvement methods } \\
\text { - Effect of machining vibration on surface quality and its control technologies } \\
\ldots . .\end{array}$ \\
\hline 5 & $\begin{array}{l}\text { Process routing } \\
\text { planning }\end{array}$ & 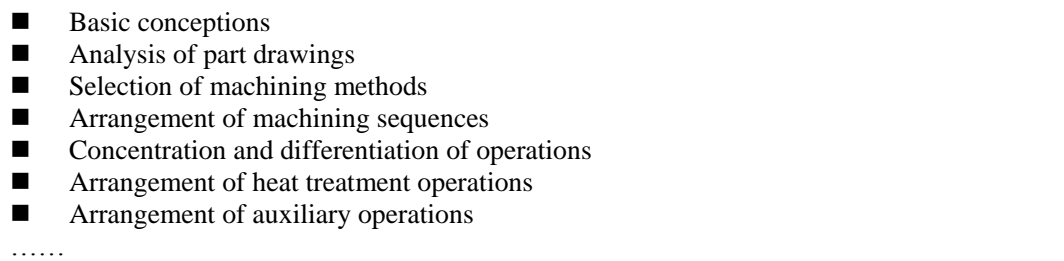 \\
\hline 6 & $\begin{array}{l}\text { Machining } \\
\text { operation design }\end{array}$ & $\begin{array}{l}\text { - Tasks involved in machining operation design } \\
\text { - Selection of machine tools and tooling } \\
\text { - Determination of machining allowances } \\
\text { - Determination of operational dimensions and tolerances } \\
\text { - Estimation of time standard } \\
\ldots . .\end{array}$ \\
\hline 7 & $\begin{array}{l}\text { Assembly process } \\
\text { planning }\end{array}$ & $\begin{array}{l}\text { - Basic conceptions } \\
\text { 口 Determination of assembly methods } \\
\text { - Planning for mechanical assembly }\end{array}$ \\
\hline
\end{tabular}

\section{Use of Teaching Means and Teaching Methods}

Teaching is a thinking activity which is carried out between teachers and students. Teachers' teaching serves as students' learning. The primary task of teachers is forcefully to enhance students' interest, consciousness and overall diathesis. In order to guarantee the teaching quality, to strengthen students' perceptual knowledge, and to train students' engineering consciousness, a variety of teaching means and teaching methods must be used in the process of teaching. 


\subsection{Teaching Means}

Teaching means is the carrier to transfer teaching information into the students. With the development of computer and information technology, the traditional teaching means have gradually been changed into the multimedia courseware. As shown in Figure 1, the multimedia courseware can show teaching contents to students by text, image, video, sound, color, animation, and so forth. However, in the process of developing the multimedia courseware, we have to pay attention to two issues: one is the selection of multimedia course notes. Generally speaking, the static and simple text notes usually have bad effects whereas colorful and animated course notes can lead the acceptation of difficult knowledge in addition to the attraction of students' attention. Another is collection of multimedia teaching materials.

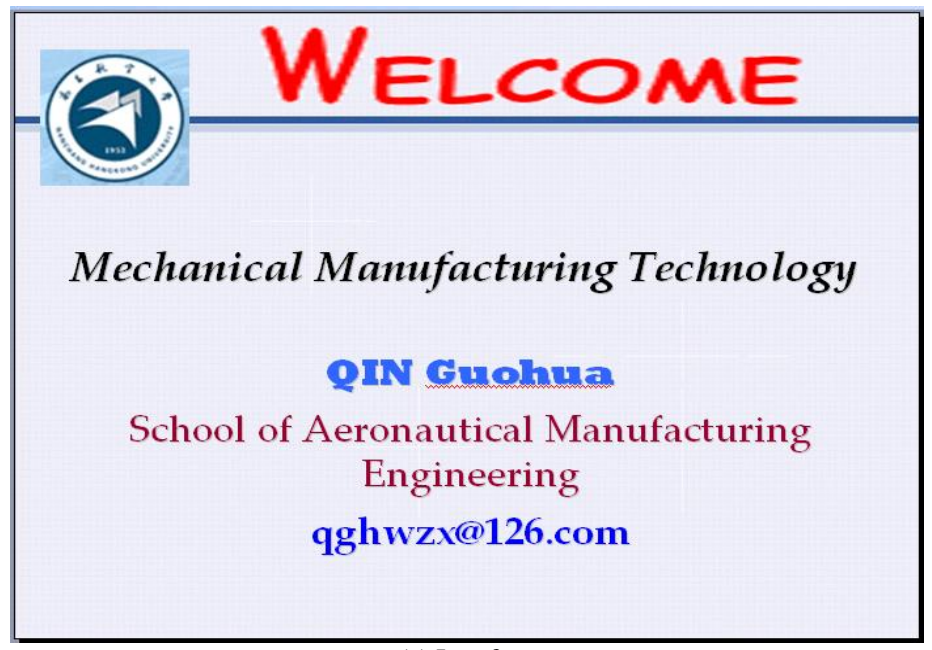

(a) Interface

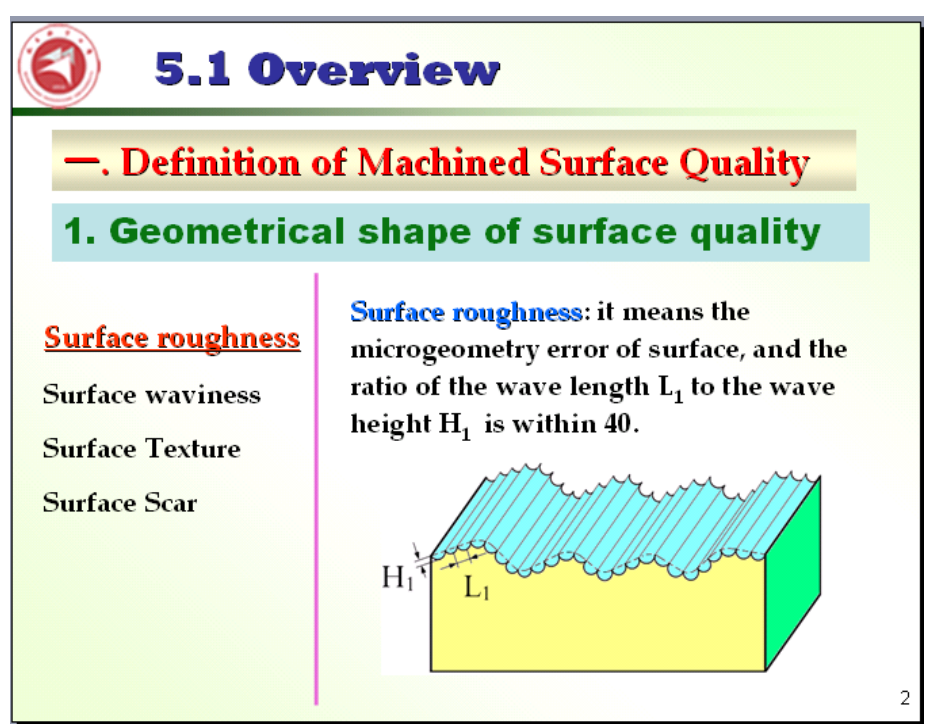

(b) Courseware design

Fig. 1. Multimedia courseware 


\subsection{Teaching Methods}

In order to train students' thinking skills, we usually adopt the guide teaching method and the analogy teaching method to enhance the teaching effect. The guide teaching method is an innovation teaching method to enlighten students learning actively [12]. Teachers can put question to students during the active teaching process. But teachers cannot immediately supply the answer to students during the vexed thinking process. Thus, the temporary frustration and worriment make students' psychology non-equilibrium such that students can centralize their attention to think the question. Thus, the guide teaching method can help students exert subjective activity. For example, why the design reference of a circle is its center? We can only remind students the method of drawing a circle with a bow compass. Thus, students should easily know that one leg forms a surface (i.e., circle) whereas another leg is naturally the design reference to determine the circle.

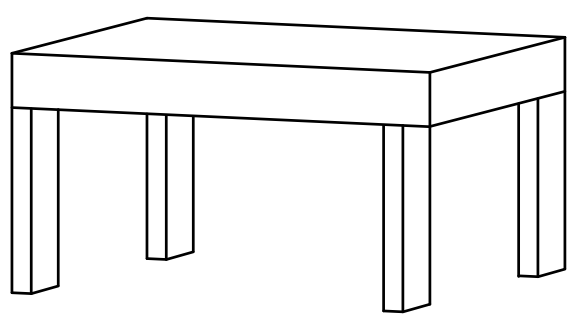

(a) Undeformed table with water

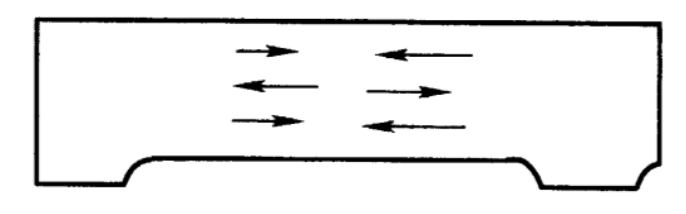

(a) Undeformed lathe bed with residual stresses

Fig. 3. Deformation caused by residual stresses

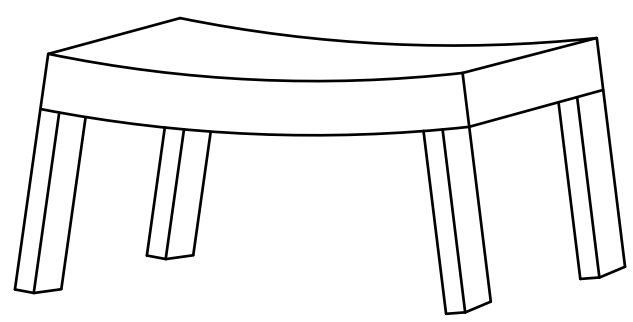

(b) Deformed table after dried

\section{Fig. 2. Deformation caused by water}

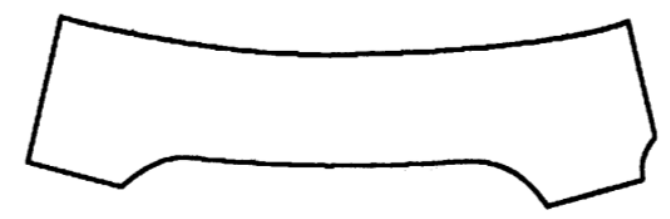

(b) Deformed lathe bed after released

The analogy teaching method is to compare one phenomenon to another phenomenon such that students can easily understand many difficult concepts and machining process. The analogy teaching method is not only an effective thinking approach to solve problems, but also a valid teaching method [13]. It can be utilized to train students' thinking skills. The residual stress and the effect of the residual stress on workpiece deformations are key point and important point of mechanical manufacturing technology. Here, we can link the residual stress in metal workpiece with the water in wood. The common knowledge told us that the wet wood cannot used to fabricate the furniture. This is because the furniture will deform after it is dried, as shown in Figure 2. Just as the lather bed with residual stress, it also cannot be machined to be a finished product. The release of residual stress can cause the finished product into deformation. Generally speaking, the distributions of residual stresses are the tensile stresses in the outer layer and the compressive stresses in the inner layer. When the machining allowance is cut from the outer layer, the redistribution of the residual stresses will cause the lathe bed to deform, as illustrated in Figure 3. 


\section{Conclusions}

Education and teaching formation is an important and arduous task in entire higher education. New teaching contents for mechanical manufacturing technology are systematically constructed to satisfy the novel talent training plan. The effective reformation strategy urges us to compile a textbook which is normally published six thousand volumes in all. On the other hand, some feasible teaching methods are discussed to understand easily mechanical manufacturing technology. As professional teachers in higher school, we must continuously learn to improve own professional knowledge. Only in doing so, can we impart more knowledge to our students.

\section{Acknowledgements}

This work is supported by the Teaching Transformation Research Project of Jiangxi Province (Grant No. JXJG-08-7-4), Teaching Transformation Research Project of Nanchang Hangkong University (Grant No. JY0820), and Aeronautical Characteristic Construction Bidding Projection of Nanchang Hangkong University (Grant No. ZB0926).

\section{References}

[1] http://baike.baidu.com/view/2954900.htm.

[2] D. W. Zuo, J. Li, and X. F. Li, "Comparison study on professional compulsory subjects in manufacturing technology among some main domestic and university," Journal of Nanjing University of Aeronautics \& Astronautics (Social Sciences), vol. 11, no. 1, pp. 87-89, March 2009. (in chinese)

[3] S. C. Zhang, Fundamentals of Mechanical Manufacturing Technology, Tianjin: Tianjin University Press, 2002. (in chinese)

[4] Z. J. Feng, Principle of Manufacturing Engineering and Technology, Beijing: Tsinghua University Press, 2004. (in chinese)

[5] Y. N. Yan, "Teaching reform in mechanical manufacturing and its fieldwork," Journal of Nanjing Institute of Technology (Social Science Edition), vol. 3, no. 4, pp. 40-43, December 2003. (in chinese)

[6] J. R. Yang, and Y. K. Zhang, "Exploration on combination of theoretical teaching and practice teaching of the foundation on the mechanical manufacturing technology course," Higher Education Forum, no. 4, pp. 86-88, April 2010. (in chinese)

[7] C. S. Hua, S. Liang, Y. N. Hu, M. Y. Duan, X. C. Wang, and W. S. Chen, "The development and reform of the new course mechanism manufacturing technology basis," Higher Education Forum, no. 4, pp. 5860, August 2004. (in chinese)

[8] M. Y. Wang, Mechanical Manufacturing Technology, Beijing: China Machine Press, 2001. (in chinese)

[9] B. H. Lu, Fundamentals of Mechanical Manufacturing Technology, Beijing: China Machine Press, 1999. (in chinese)

[10] G. H. Qin, and D. Lu, Mechanical Manufacturing Technology (The First Press), Beijing: National Defense Industry Press, 2009. (in chinese)

[11] G. H. Qin, and D. Lu, Mechanical Manufacturing Technology (The Second Press), Beijing: National Defense Industry Press, 2010. (in chinese)

[12] C. Y. Chen, "Evaluation on efficiency of guide teaching in hydraulics course," Journal of Wuhan Polytechnic, vol. 8, no. 6, pp. 54-56+60, June 2009. (in chinese)

[13] J. M. Jia, "The application of analogy in the hydraulic transmission teaching," Journal of Changzhou Vocational College of Information Technology, vol. 6, no. 3, pp. 70-72, March 2007. (in chinese) 